ONLINE MUTATION REPORT

\title{
Molecular alterations in mitochondrial DNA of hepatocellular carcinomas: is there a correlation with clinicopathological profile?
}

\author{
L-J C Wong, D-J Tan, R-K Bai, K-T Yeh, J Chang
}

J Med Genet 2004;41:e65 (http://www.jmedgenet.com/cgi/content/full/41/5/e65). doi: 10.1136/jmg.2003.013532

$M$ olecular defects in the mitochondrial genome responsible for a broad clinical spectrum of maternally inherited neuromuscular mitochondrial disorders have been documented extensively. ${ }^{12}$ Mitochondrial dysfunction causes cellular degeneration, particularly in nerve and muscle cells that have a high demand for energy. The role of the mitochondria in apoptotic pathways, and the identification of tumour suppressing functions of several genes involved in metabolism, suggests that mutant mitochondria are at the crossroads of tumorigenesis and programmed cell death.

In recent years, numerous reports on somatic mtDNA mutations in cancers have supported the concept that somatic mtDNA alterations are an integral part of tumorigenesis. $^{3-12}$ Extensive analysis of the mitochondrial genome with direct sequencing has shown that about $30-70 \%$ of all types of tumours harbour alterations in mtDNA. ${ }^{3-13}$ The laborious effort involved in sequencing the entire mitochondrial genome means that mutational analyses usually have been performed on small numbers of specimens and were limited to only part of the mitochondrial genome. Most of these studies focused on the hypervariable, non-coding Dloop region only. ${ }^{3-10} 1314$ The only comprehensive mutational analysis that covered the entire mitochondrial genome with overlapping primers was achieved recently with the use of the effective temperature gradient gel electrophoresis method. ${ }^{15-17}$ Previous reports showed that most of the somatic mtDNA mutations found in patients with cancer were in the homoplasmic form..$^{71}$ This observation led to the conclusion that mutant mitochondria gained a replicative advantage during tumorigenesis and became homoplasmic within a few generations. ${ }^{7}$ Our recent comprehensive investigation of somatic mtDNA mutations in breast tumours and medulloblastomas showed that mutations in the coding region did occur, as did a significant number of heteroplasmic alterations. ${ }^{4} 16$

Results from others' and our own studies of various types of cancers suggest that the somatic mtDNA mutation spectrum may vary among different tissues. ${ }^{4} 911161819$ Human hepatocellular carcinoma is unique, in that the cancer usually is preceded by chronic infection or other liver diseases for 20-40 years. The liver is also the site for metabolism and detoxification of numerous drugs and carcinogens. Development of hepatocellular carcinoma is rapid. We hypothesised that the higher oxidative stress associated with carcinogenesis in patients with chronic liver disease may result in a unique spectrum of mtDNA mutations. Somatic mtDNA mutations in patients with hepatocellular carcinoma have been investigated and two studies found that $17 / 50(34 \%)$ and $13 / 19$ (68\%) patients with hepatocellular carcinoma harboured somatic mtDNA mutations. $^{2021}$ These studies were restricted to the Dloop region only and were performed by sequencing that might

\section{Key points}

- Somatic mitochondrial DNA (mtDNA) alterations were investigated in patients with hepatocellular carcinomas and the molecular changes in mtDNA were correlated with the clinicopathological profile of patients with hepatocellular carcinomas.

- The entire mitochondrial genome from 20 pairs of hepatocellular carcinomas and their surrounding tissues was amplified by using 32 pairs of overlapping primers. Somatic mutations were detected by temporal temperature gradient gel electrophoresis. Fragments of mtDNA that had different banding patterns for tissue in the tumour and the non-cancerous tissue that surrounded the tumour were sequenced to identify mutations.

- Of 20 hepatocellular carcinomas, 10 (50\%) had somatic mtDNA mutations, with a total of 24 mutations found. All mutations except one were in the non-coding Dloop region. Five tumours harboured mutations in the np303-309 poly $C$ hot spot. A novel mutation in the np433-438 poly $C$ stretch region that was seen in three hepatocellular carcinomas had never been reported in other tumours. This mutation located in the mtTFl transcription factor binding site may be unique to hepatocellular carcinoma.

- Quantitative analysis showed that tumours with miDNA mutations contained markedly higher or significantly lower amounts of mtDNA than the surrounding tissues. The presence of mtDNA mutations did not seem to correlate with the patient's age or sex, the tumour's size or grade, or the patient's survival.

- Two patients identified as alcoholics harboured numerous mtDNA mutations. Two of the three tumours with mtDNA mutations and markedly elevated mtDNA content were also in patients infected with hepatitis B.

- The alteration in content of mtDNA may be related to the mutations in the Dloop region. As most hepatocellular carcinomas usually are preceded by chronic infection or other liver disease, our results suggest that qualitative alterations or quantitative alterations in mtDNA, or both, may play an important role in tumorigenesis in individual patients with other associated liver diseases.

not have detected a low proportion of heteroplasmy. In this report, we used our comprehensive temperature gradient gel electrophoresis method to investigate mtDNA mutations in 
the entire mitochondrial genome of primary hepatocellular carcinomas and the surrounding tissue in 20 patients. We also evaluated the mtDNA content in the tumour and its surrounding tissue and correlated the molecular findings with the clinicopathological profile of the tumour.

\section{MATERIALS AND METHODS}

\section{Tissue specimens and DNA extraction}

We used paired tumours and surrounding tissues that were previously banked specimens surgically removed and histologically confirmed from patients with hepatocellular carcinoma. The patients ranged in age from 29 to 74 (average 59 (SD 14)) years; five were women and 15 men. We obtained specimens from the tumour bank of the pathology department of Changhua Christian Hospital, Changhua, Taiwan, according to an institutionally approved protocol. All tissues were snap frozen in liquid nitrogen and stored at $-80^{\circ} \mathrm{C}$ until they were analysed. We isolated DNA from frozen tissues with proteinase $\mathrm{K}$ digestion and phenol and chloroform extraction. We quantified total DNA with fluorescent Hoechst dye H33258 (Sigma, St Louis, MO, USA) and a Dyna Quant 200 Fluorometer (Amersham Biosciences, Little Chalfont, UK), according to the manufacturer's protocol. We diluted DNA to $5 \mathrm{ng} / \mu \mathrm{l}$ for use in polymerase chain reactions (PCR).

\section{Comprehensive mutational analysis of the entire mitochondrial genome}

Comprehensive mutation analysis of the entire mitochondrial genome by temporal temperature gradient gel electrophoresis has been described previously. ${ }^{15}{ }^{17}$ We used 32 pairs of overlapping primers to amplify the entire $16.6 \mathrm{~kb}$ mitochondrial genome. The DNA fragments ranged in size from 306 to 805 (average 594) bp. ${ }^{15}{ }^{17}$ Each fragment has an average of $74 \mathrm{bp}$ on each end that overlaps with neighbouring fragments. We denatured PCR products at $95^{\circ} \mathrm{C}$ for 30 seconds and slowly cooled them to $45^{\circ} \mathrm{C}$ over 45 minutes at a rate of $1.1^{\circ} \mathrm{C} /$ minute. We performed temporal temperature gradient gel electrophoresis on a Bio-Rad D-Code apparatus (Bio-Rad Laboratories, Hercules, CA, USA). We prepared polyacrylamide (acrylamide:bisacrylamide 37.5:1) gels in $1.2 \times$ Tris-acetateethylene diamine tetraacetic acid buffer that contained $6 \mathrm{~mol} / \mathrm{l}$ urea. We carried out electrophoresis at $135 \mathrm{~V}$ for 4-6 hours at a constant temperature increment of $1-2^{\circ} \mathrm{C} /$ hours. The start and end temperatures were determined by computer simulation from the melting curve $(50 \%$ denatured) of the DNA fragment. ${ }^{15}$ On analysis with temporal temperature gradient gel electrophoresis, a single band shift represents a homoplasmic DNA alteration and a multiple banded pattern represents a heteroplasmic mutation. We analysed the DNA fragments from the tumour and surrounding tissues of the same patient side by side.

\section{Identification of mutations by DNA sequencing}

We sequenced any DNA fragments that had differences in banding patterns between samples from tumours and the surrounding tissues to identify the exact mutations. We performed DNA sequencing by using the Big Dye Terminator Cycle Sequencing Kit (Perkin Elmer, Wellesley, MA, USA) and an ABI 377 (Applied Biosystems, Foster City, CA, USA) automated sequencer. The results of DNA sequence analysis were compared with the revised human mitochondrial Cambridge reference sequence deposited in GenBank (accession number NC $\phi \phi 18 \phi 7$ ) 22 by using MacVector (version 7.0; Oxford Molecular, Oxford, England). We score any DNA sequence differences between mtDNA from tumours and matched normal tissues as somatic mutations and sequence variations in mtDNA from tumours and matched normal tissues that were different from those recorded in GenBank as germline variations. We checked each mutation against the Mitomap database (http://www.mitomap.org). Mutations not recorded in the database were categorised as novel mtDNA variations and those that appeared in the database as reported polymorphisms or mutations.

\section{Measurement of mtDNA contents in tumours and surrounding tissue}

We determined the mtDNA content with real time quantitative PCR analysis ${ }^{23}$ with an ABI Sequence Detection System 7700 (Applied Biosystems, Foster City, CA, USA); the content was expressed as the ratio of copy numbers of mtDNA to copy numbers of $18 \mathrm{~S}$ rRNA gene (nDNA). The mtDNA/18SrDNA ratio in tumour was divided by the ratio in the surrounding non-cancerous tissue to obtain the ratio of the amount of mtDNA in tumour to that in normal tissue. A ratio $>1$ meant that more mtDNA was present in a tumour than in the surrounding tissue. A ratio $<1$ meant that less mtDNA was present in a tumour compared with its surrounding noncancerous tissue.

\section{RESULTS \\ Somatic mtDNA mutations in hepatocellular carcinomas}

We used the temporal temperature gradient gel electrophoresis mutation detection method to screen the entire mitochondrial genome of tumour and surrounding normal tissues to test whether somatic mtDNA mutations are a general phenomenon in hepatocellular carcinomas and to characterise the mutation spectrum. We found a number of differences in the banding patterns between tumours and surrounding tissues (fig 1). We noted homoplasmy to heteroplasmy changes in panels $\mathrm{A}$ and $\mathrm{C}$, a homoplasmy to homoplasmy alteration shown as a band shift in panel B, and a change in the degree of heteroplasmy in panel D. We direct sequenced the DNA fragment to identify the mutations (fig l; table 1). Of the 20 tumours, $10(50 \%)$ harboured somatic mtDNA mutations, with a total of 24 mutations. All but one of the mutations were in the Dloop region. We sequenced 30 DNA fragments that did not have banding patterns that differed between the tumour and the surrounding tissue. We detected no somatic mutations. Of the 10 tumours found to have somatic mutations, seven had one somatic mutation, one had two mutations, one had five mutations, and another had 10 mutations (table 1).

An insertion or deletion within the poly $\mathrm{C}$ stretch occurred five times in the np303-309 hot spot region and three times in np433-438. The alteration in the np433-438 poly $\mathrm{C}$ region is novel and has never been reported in any other tumours studied. This occurred at the transcription factor mtTFl binding site. Interestingly, C194T, T195C, and C199T occurred simultaneously in two tumours: HE12 and HE19, which had five and 10 different somatic mtDNA mutations, respectively. This was also seen with T204C and G207A mutations, which occurred simultaneously in 3/18 NF1 neurofibromas, 1/19 breast tumours, and 1/20 hepatocellular carcinomas in this study. ${ }^{41924}$ The significance of simultaneous somatic mutations at multiple positions is not clear. A $310 \mathrm{~T}$ to $\mathrm{C}$ transition in tumour HE11 resulted in a stretch of $13 \mathrm{C}$ at np303-315. The long stretch of poly $\mathrm{C}$ might increase the instability of this region. The np514-523insCACACA, which lengthened the CA repeat from four repeats to seven repeats, also was unusual. Of the somatic mutations, 16 were changed from the homoplasmic state in the surrounding tissue to a mutant homoplasmic state in the tumour, three from the heteroplasmic state in normal tissue to the homoplasmic state in the tumour, and four from the homoplasmic wild type to heteroplasmic mutants. One had quantitatively different proportions of mutant mtDNA in the heteroplasmic state in the surrounding tissue and in the tumour. These results were 

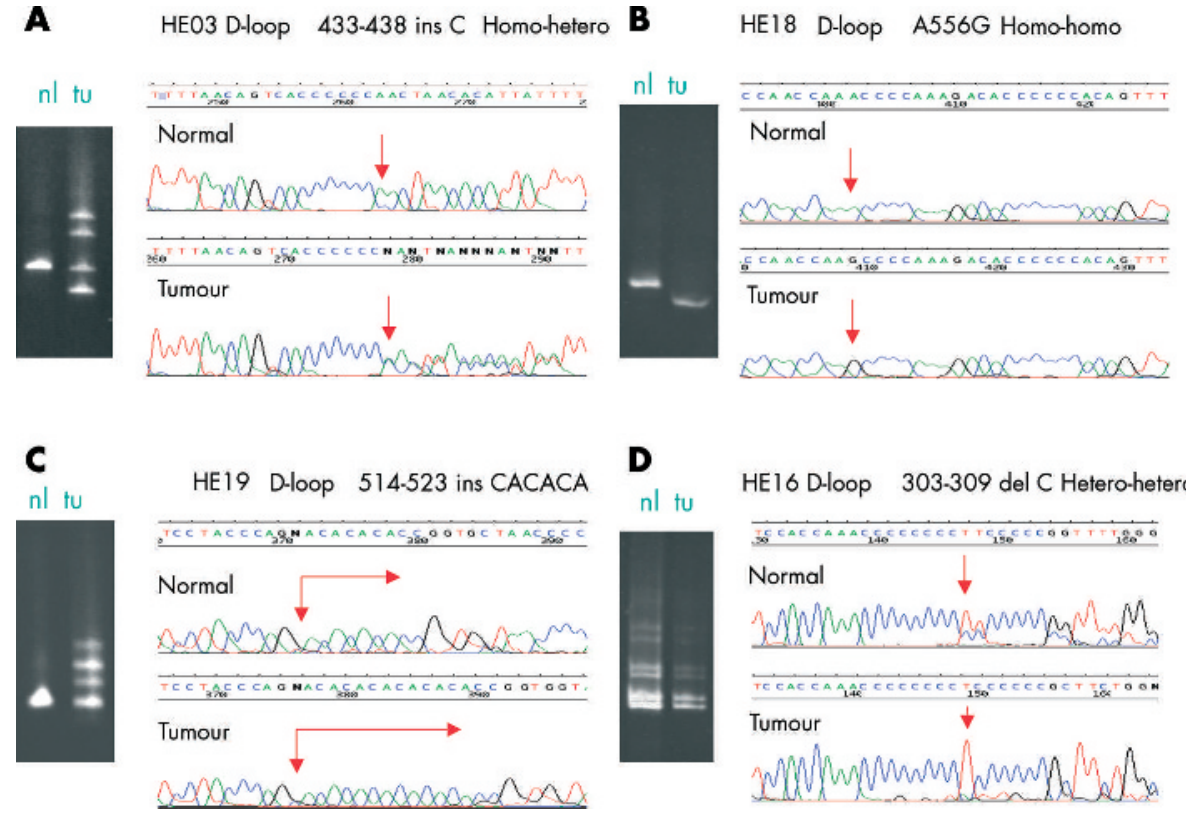

HE16 D-loop 303-309 del C Hetero-hetero

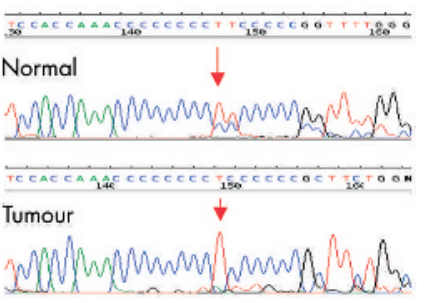

Figure 1 Detection and sequence identification of somatic mtDNA mutations by temporal temperature gradient gel electrophoresis in patients with liver cancer. (A) Homoplasmic to heteroplasmic insertion of cytidine at np433-438; the multiple banding pattern from temporal temperature gradient gel electrophoresis confirmed heteroplasmic change. (B) Homoplasmy to homoplasmy change of A556G; the single band shift on temporal temperature gradient gel electrophoresis is typical of homoplasmic alteration. (C) Heteroplasmic insertion of CACACA at np514-523. (D) Change in degree of heteroplasmy shown by the change in the signal intensities of heteroduplex and homoduplex bands.

consistent with random occurrences of mtDNA alterations at different times during tumorigenesis or with mutations that might become homoplasmic at different rates. The mutant mitochondria might be present in the homoplasmic or heteroplasmic states depending on the number of cell divisions they have gone through and their replicative advantage.

\section{Germline sequence variations}

When we compared the sequence of surrounding tissue with the revised Cambridge mtDNA reference sequence deposited in GenBank (accession number NC $\phi \phi 18 \phi 7$ ), we found numerous germline sequence variations. A total of 145 distinct germline variations have been identified from the sequenced fragments. These do not represent all the sequence variations in the specimens analysed, as we sequenced only the DNA regions that showed somatic mutations by temporal temperature gradient gel electrophoresis. Twelve of these variations were novel (table 2), and 133 of were recorded in the Mitomap database (data not shown). Eight of these novel variations occurred in the mRNA region, and three were missense variations (table 2). The np248-249delA variation was detected in 6/20 hepatocellular carcinomas. This germline variation was not detected in 19 breast cancers, 31 NFl neurofibromas, and 15 medulloblastomas, all of Caucasian origin, ${ }^{4}{ }^{16} 19$ but it was detected in 3/27 (11\%) patients with breast cancer, 4/20 (20\%) with oesophageal cancer, and 2/18 (11\%) with oral cancer from Taiwan. ${ }^{18}$ The frequency of the np248-249delA variation in the Taiwanese population was $17.4 \%$. Although the difference in frequency was not statistically significant, this polymorphism was in the mtTF 1 transcription factor binding site. Sequence variation in this region may influence the efficiency of transcription.

\section{MrDNA mutation spectrum among various tumors}

The mtDNA mutation spectrum in patients with hepatocellular carcinoma was compared with that found in other cancers (table 3 ). The somatic mtDNA mutations were found in $41-78 \%$ of various tumours, with most of the mutations
(58-100\%) in the non-coding Dloop region, except in patients with bladder cancer.48911 ${ }^{4161819}$ Missense or nonsense mutations were not identified in patients with liver cancer. Similarly, in benign neurofibromas, all mtDNA mutations identified so far have been in the non-coding Dloop region. ${ }^{19}$ Missense or nonsense mutations, although they do not occur often, most likely are functionally significant. Mutations in the Dloop region may affect mtDNA replication and transcription and thus alter mitochondrial biogenesis and gene expression.

\section{MrDNA content in hepatocellular carcinoma}

We compared the amount of mtDNA in tumours with that in the surrounding non-cancerous tissue by real time quantitative PCR analysis to investigate if mtDNA mutations in the non-coding region affect mtDNA copy numbers. Table 4 lists the number of somatic mutations and the ratio of mtDNA copy numbers to nuclear DNA (18S rDNA) copy numbers. The mean ratio of mtDNA to $18 \mathrm{~S}$ rDNA in the tumours with mtDNA mutations was 1.19 (SD 0.32) and in tumours without mtDNA mutation was $0.77(0.12)$; the overall average was $0.98(0.17)$. No significant difference was seen between the two groups of tumours with or without mtDNA mutations $(p=0.24)$. The tumours with somatic mtDNA mutations contained markedly increased or decreased amounts of mtDNA (five tumours had ratios $>1.2$ and five $<0.7$ ). All except one of the six samples that had larger amounts of mtDNA content in the tumour tissue than in the surrounding tissue harboured detectable mtDNA mutations. Three of the six tumours contained more than twice as much mtDNA as the surrounding tissues, and all had mtDNA mutations. Another tumour contained 1.88 times as much mtDNA as the surrounding tissue and also harboured a Dloop mutation. This difference between mtDNA content of tumours with and without mtDNA mutations was statistically significant $(\mathrm{p}=0.021)$. These data suggest that alterations in the Dloop region probably affect mtDNA replication, which causes increases or decreases in the content of mtDNA in tumours compared with normal tissue. 
Table 1 Somatic mtDNA mutations in patients with liver cancer

\begin{tabular}{|c|c|c|c|c|c|c|}
\hline Case & Gene & $\begin{array}{l}\text { Difference between DNA in } \\
\text { tumours and in normal tissue }\end{array}$ & $\begin{array}{l}\text { Cambridge } \\
\text { sequence }\end{array}$ & Pattern & Function location & Reported in Mitomap and other fumours \\
\hline HEO1 & $\mathrm{COl}$ & T6293C (CCT>CCC, P130P) & $\mathrm{T}$ & $\mathrm{Hm}$ to $\mathrm{Ht}$ & $\mathrm{COI}$ & Novel \\
\hline HEO2 & Dloop & A16180G & A & $\mathrm{Hm}$ to $\mathrm{Hm}$ & $7 S$ & \\
\hline HEO3 & Dloop & $433>438$ ins $C\left(C_{6}>C_{6 / 7}\right)$ & $\mathrm{C}_{6}$ & $\mathrm{Hm}$ to $\mathrm{Ht}$ & $\mathrm{mtTF1}$ binding site & Novel \\
\hline HEO9 & Dloop & $303>309$ ins $C\left(C_{7}>C_{7 / 8}\right)$ & $\mathrm{C}_{7}$ & $\mathrm{Hm}$ to $\mathrm{Ht}$ & mtTFl binding site & $\begin{array}{l}\text { Breast, head and neck, colon, ovarian cancer, lung, } \\
\text { gastric, and thyroid cancers }\end{array}$ \\
\hline HE11 & Dloop & $303>315$ del $C\left(C_{13}>C_{12}\right)$ & $\mathrm{C}_{7} \mathrm{TC}_{5}$ & $\mathrm{Hm}$ to $\mathrm{Hm}$ & mtTF1 binding site & $\begin{array}{l}\text { Breast, head and neck, colon, ovarian cancer, lung, } \\
\text { gastric, and thyroid cancers }\end{array}$ \\
\hline $\mathrm{HE} 12$ & Dloop & $\mathrm{C} 194 \mathrm{~T}$ & C & $\mathrm{Hm}$ to $\mathrm{Hm}$ & $\mathrm{H}$ to strand origin & \\
\hline HE12 & Dloop & $\mathrm{T} 195 \mathrm{C}$ & $\mathrm{T}$ & $\mathrm{Hm}$ to $\mathrm{Hm}$ & $\mathrm{H}$ to strand origin & Breast cancer and glioblastomas \\
\hline HE12 & Dloop & C199T & $\mathrm{T}$ & $\mathrm{Ht}$ to $\mathrm{Hm}$ & $\mathrm{H}$ to strand origin & Ovarian cancer \\
\hline HE12 & Dloop & G263A & A & $\mathrm{Hm}$ to $\mathrm{Hm}$ & $\mathrm{H}$ to strand origin & \\
\hline HE12 & Dloop & $303>309$ del $C\left(C_{8 / 7}>C_{7}\right)$ & $\mathrm{C}_{7}$ & $\mathrm{Ht}$ to $\mathrm{Hm}$ & mtTFl binding site & $\begin{array}{l}\text { Breast, head and neck, colon, ovarian cancer, lung, } \\
\text { gastric, and thyroid cancers }\end{array}$ \\
\hline HE16 & Dloop & $303>309$ del $C\left(C_{8 / 9}>C_{8}\right)$ & $\mathrm{C}_{7}$ & $\mathrm{Ht}$ to $\mathrm{Ht}$ & mtTFl binding site & $\begin{array}{l}\text { Breast, head and neck, colon, ovarian cancer, lung, } \\
\text { gastric, and thyroid cancers }\end{array}$ \\
\hline HE18 & Dloop & $433>438$ ins $C\left(C_{6}>C_{7}\right)$ & $\mathrm{C}_{6}$ & $\mathrm{Hm}$ to $\mathrm{Hm}$ & mtTFl binding site & Novel \\
\hline HE18 & Dloop & A556G & A & $\mathrm{Hm}$ to $\mathrm{Hm}$ & $\begin{array}{l}\text { Major } \mathrm{H} \text { to strand } \\
\text { promoter }\end{array}$ & Novel \\
\hline HE19 & Dloop & A189G & $A$ & $\mathrm{Hm}$ to $\mathrm{Hm}$ & $\mathrm{H}$ to strand origin & Breast cancer \\
\hline HE19 & Dloop & C194T & C & $\mathrm{Hm}$ to $\mathrm{Hm}$ & $\mathrm{H}$ to strand origin & \\
\hline HE19 & Dloop & T195C & $\mathrm{T}$ & $\mathrm{Hm}$ to $\mathrm{Hm}$ & $\mathrm{H}$ to strand origin & Breast cancer and glioblastomas \\
\hline HE19 & Dloop & T199C & $\mathrm{T}$ & $\mathrm{Hm}$ to $\mathrm{Hm}$ & $\mathrm{H}$ to strand origin & Ovarian cancer \\
\hline HE19 & Dloop & T204C & $\mathrm{T}$ & $\mathrm{Ht}$ to $\mathrm{Hm}$ & $\mathrm{H}$ to strand origin & Breast cancer and glioblastomas \\
\hline HE19 & Dloop & G207A & G & $\mathrm{Hm}$ to $\mathrm{Hm}$ & $\mathrm{H}$ to strand origin & Breast and thyroid cancers \\
\hline HE19 & Dloop & $433>438$ del $C\left(C_{7}>C_{6}\right)$ & $\mathrm{C}_{6}$ & $\mathrm{Hm}$ to $\mathrm{Hm}$ & mtTFl binding site & Novel \\
\hline HE19 & Dloop & $\mathrm{T} 456 \mathrm{C}$ & $\mathrm{C}$ & $\mathrm{Hm}$ to $\mathrm{Hm}$ & & Thyroid cancer \\
\hline HE19 & Dloop & C489T & & $\mathrm{Hm}$ to $\mathrm{Hm}$ & & Ovarian cancer \\
\hline HE19 & Dloop & $\begin{array}{l}514>523 \text { ins }(C A)_{3} \\
\left((C A)_{4}>(C A)_{7}\right)\end{array}$ & $(\mathrm{CA})_{5}$ & $\mathrm{Hm}$ to $\mathrm{Hm}$ & & $\begin{array}{l}\text { Ovarian cancer, thyroid, head and neck, and } \\
\text { gastric cancers }\end{array}$ \\
\hline HE2O & Dloop & $303->309$ ins $C\left(C_{8}->C_{8 / 9}\right)$ & $\mathrm{C}_{7}$ & $\mathrm{Hm}$ to $\mathrm{Ht}$ & mtTF1 binding site & $\begin{array}{l}\text { Breast, head and neck, colon, ovarian cancer, lung, } \\
\text { gastric, and thyroid cancers }\end{array}$ \\
\hline \multicolumn{7}{|c|}{$\begin{array}{l}\text { Ht, heteroplasmy } \\
\text { Hm, homoplasmy. } \\
\text { Twenty-four mutations in total, four homoplasmy to heteroplasmy, three heteroplasmy to homoplasmy, } 16 \text { homoplasmy to homoplasmy, and one heteroplasmy to } \\
\text { heteroplasmy. }\end{array}$} \\
\hline
\end{tabular}

\section{Correlation of qualitative and quantitative changes of mtDNA with clinicopathological findings}

Table 4 summarises the tumour size, grade, stage, and length of survival, as well as the associated liver disease of patients. The change in mtDNA content in these tumours was not related to age, sex, tumour size, or survival of the patients, but it did correlate well with the presence of mtDNA mutations as stated above. The presence of mtDNA mutations is not associated with metastatic status of the tumours. Hepatitis B infection alone did not seem to correlate with the mtDNA content or presence of mtDNA mutations. Three patients with mtDNA mutations who had more than twice as much mtDNA content in the tumours as in the surrounding tissues were neither infected with hepatitis B nor had liver cirrhosis. Three of four patients who had mtDNA mutations and less mtDNA in the tumours than the surrounding tissue also were infected with hepatitis B. The youngest patient in this study, HE-5 (aged 29 years), had more mtDNA in the tumour than the surrounding tissue but did not have an mtDNA point mutation (table 4).

Participant HE19 harboured 10 mtDNA mutations. He had a medical history of alcohol induced liver disease. Pathological examination on admission to hospital showed a primary hepatocellular carcinoma (not a metastasis of oesophageal tumour) in S4 and an oesophageal squamous cell carcinoma in the mid-segment of the oesophagus. He

Table 2 Novel germline sequence variations in patients with hepatocellular carcinomas

\begin{tabular}{|c|c|c|c|c|c|}
\hline Case & Gene & Polymorphism & Codon & AA change & Function \\
\hline HElO & Dloop & T146A & & & $\mathrm{H}$ strand origin \\
\hline $\mathrm{HEl} 4$ & Dloop & A259G & & & mtTFl binding site \\
\hline $\mathrm{HE} 14$ & Dloop & $\mathrm{T} 504 \mathrm{C}$ & & & \\
\hline HEOI & $\mathrm{COl}$ & A6338G & $\mathrm{CTA}>\mathrm{CTG}$ & L145L & Cyłochrome c oxidase subunit I \\
\hline $\mathrm{HE} 17$ & COIII & A9254G & TGA $>$ TGG & W16W & Cytochrome c oxidase subunit III \\
\hline HEl7 & COIII & T9530C & $\mathrm{CCT}>\mathrm{CCC}$ & P108P & Cytochrome $\mathrm{c}$ oxidase subunit III \\
\hline HEl9 & ND3 & A10153C & $\mathrm{GAA}>\mathrm{GCA}$ & E32A & $\begin{array}{l}\text { Nicotinamide adenine dinucleotide } \\
\text { dehydrogenase subunit } 3\end{array}$ \\
\hline HE19 & ND4 & Al1015G & AGT $>$ GGT & S86A & $\begin{array}{l}\text { Nicotinamide adenine dinucleotide } \\
\text { dehydrogenase subunit } 4\end{array}$ \\
\hline HE17 & ND6 & Al4388G & $\Pi \mathrm{TA}>\mathrm{CTA}$ & L96L & $\begin{array}{l}\text { Nicotinamide adenine dinucleotide } \\
\text { dehydrogenase subunit } 6\end{array}$ \\
\hline HEl7 & $\mathrm{E}$ & A14679G & & & tRNA glutamic acid \\
\hline HE2O & CYTB & G15323A & $\mathrm{GCA}>\mathrm{ACA}$ & А193T & Cytochrome b \\
\hline $\mathrm{HE} 16$ & CYTB & A15859G & $\mathrm{CTA}>\mathrm{CTG}$ & L371L & Cytochrome b \\
\hline
\end{tabular}


Table 3 Summary of somatic mitochondrial DNA mutations in various tumours. Values are numbers (percentages)

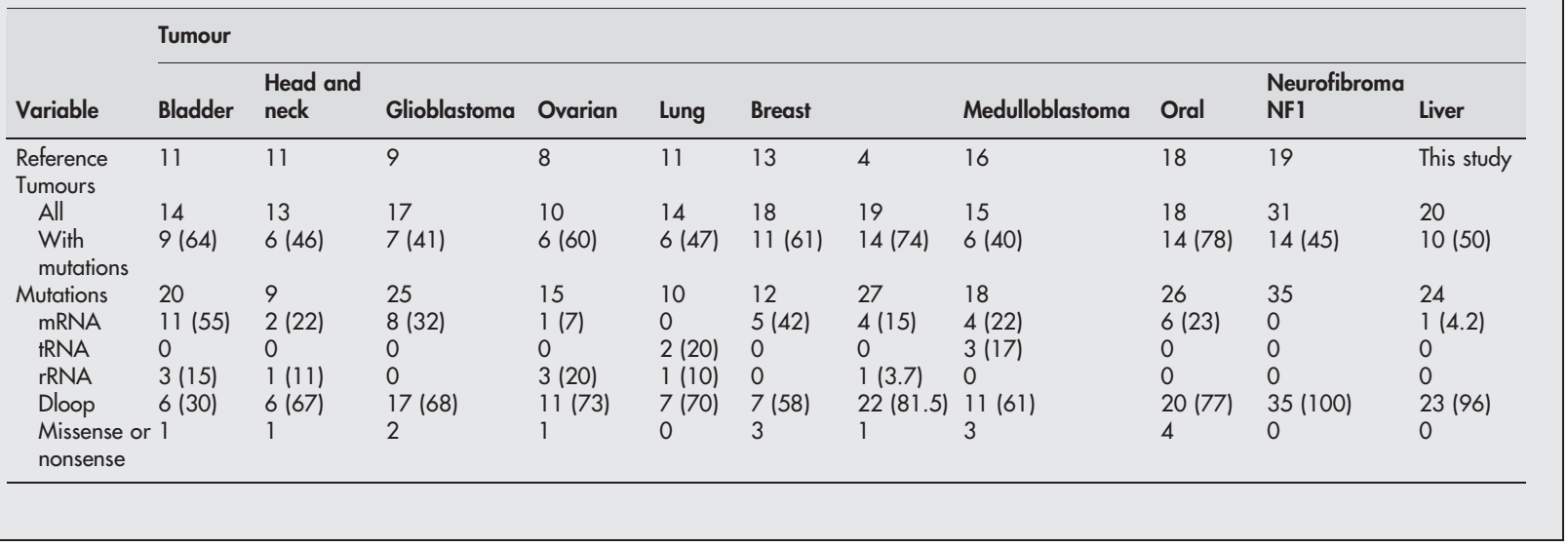

underwent surgical removal of the tumours and received several courses of concurrent radiotherapy and chemotherapy. The oesophageal squamous cell carcinoma metastasised to multiple organs and the patient died three years later. Participant HE12 also had a history of alcohol abuse and harboured five mtDNA mutations. The occurrence of multiple mtDNA mutations in the tumour tissues was not caused by radiotherapy, because the DNA was extracted from tumour tissue removed before they underwent radiotherapy. Overall, 16 mtDNA mutations were found in three of the five patients with a history of alcohol abuse and eight mtDNA mutations in seven of 14 patients without alcohol related liver disease $(\mathrm{p}=0.025)$.

\section{DISCUSSION}

This is the first report on comprehensive mtDNA mutational analysis of patients with hepatocellular carcinomas. We screened the entire mitochondrial genome of 20 patients with hepatocellular carcinomas and their surrounding tissues for the presence of somatic mutations with the effective temporal temperature gradient gel electrophoresis mutation detection method. We identified somatic mtDNA mutations in $10 / 20(50 \%)$ of patients with hepatocellular carcinoma. Several heteroplasmic alterations were detected (table 1). The frequency of homoplasmic to homoplasmic changes probably depends on the type of tumour. We previously reported low frequencies of homoplasmic to homoplasmic alterations in patients with oral cancer (11.5\%), NF1 neurofibroma (46\%), and breast cancer and medulloblastoma (44.4\%). ${ }^{16} 1819$ In this study, we found homoplasmic to homoplasmic changes in 16/24 (67\%) mutations. Previous reports on the study of somatic mtDNA mutations in patients with liver cancer were limited to the analysis of the non-coding Dloop region. ${ }^{20} 2125$ Okochi et al. detected somatic Dloop mtDNA mutations in $17 / 50(34 \%)$ patients with hepatocellular carcinoma and Nomoto et al. reported mtDNA mutations in 13/19 (68\%) patients with hepatocellular carcinoma. ${ }^{20}{ }^{21}$ We screened the entire mitochondrial genome and detected mtDNA mutations in 10/20 (50\%) of patients with hepatocellular carcinoma. Of the somatic mutations, $96 \%$ were in the Dloop; this rate is much higher than found in other tumours (table 3). Our results suggest that somatic mtDNA mutations in liver cancer concentrate in the Dloop region.

The mononucleotide repeat between np303 and 309 is among the most unstable microsatellite regions. This homopolymeric $\mathrm{C}$ stretch is part of the conserved sequence block II located within the regulatory Dloop region and is involved in the formation of a persistent RNA-DNA hybrid that leads to the initiation of mtDNA heavy strand replication. ${ }^{26}$
Alterations in this region could lead to replicative advantage of the mutant mitochondria in tumour cells. In this study, we found an insertion or deletion at the np303-309 poly C tract region in 5/20 (25\%) tumours compared with $16 \%$ and $42 \%$ in recent reports. ${ }^{20}{ }^{21}$ Sanchez-Cespedes et al. studied the frequency of somatic insertions at np303-309 and found that they occurred at rates of $62.5 \%, 29 \%, 28 \%, 16 \%, 20 \%, 0 \%$, and $0 \%$ in gastric, breast, colorectal, lung, bladder, prostate, and ovarian cancers, respectively. ${ }^{27}$ Our previous study showed that $21 \%$ of breast tumours have an insertion or deletion of cytidine in this region. ${ }^{4}$ Insertion and deletion rarely occurs in other homopolymer regions. We confirmed this result by sequencing six mtDNA regions that contained the poly mononucleotide tracts (CA $)_{5-7}$ at np 514-523, $\mathrm{C}_{6-7}$ at np 3566, $A_{7}$ at np6692, $T_{7}$ at np9478, $A_{8}$ at np12418, $C_{6}$ at np12385, $\mathrm{C}_{8-14}$ at np16184, and (CCT) ${ }_{3}(\mathrm{AGC})_{3}$ at np12981 in 1-6 tumours each. These results suggest that the instability at np303-309 probably is not because of generalised microsatellite instability but rather is because it is located at the triple strand displacement loop-a region that is relatively unstable. The somatic mtDNA mutations seen in tumours are not PCR artefacts, because we analysed mtDNA in at least 50 muscle and blood specimens of people of various ages, and somatic mtDNA mutations were found in $<2 \%$ of samples. Our observations substantiate the concept of chromosomal and genomic instability in tumour tissues, including the mitochondrial genome.

The relation between the length of the poly $\mathrm{C}$ stretch at np303-309 and tumorigenesis is not clear. Variations in length in this region may play an important role in regulating mtDNA replication. For example, patient HEll, who had a long stretch of $12 \mathrm{C}$ without the interruption of a $\mathrm{T}$ at $\mathrm{np} 310$ in the tumour, had large amounts of mtDNA. The other unstable microsatellite in the Dloop region that was altered in three tumours (participants HE3, HE18, and HE19) was the np433-438 poly $C$ region at the mtTFl transcription factor binding site. This was the only mtDNA mutation in participant HE3, who had a relatively small but metastatic tumour $\left(2 \times 1.7 \times 1.2 \mathrm{~cm}^{3}\right)$ and almost three times as much mtDNA in the tumour as the surrounding tissues. Patient H18 harboured another novel mutation, A556G, at the major $\mathrm{H}$ strand promoter region. This patient had a huge tumour $\left(20 \times 12 \times 5 \mathrm{~cm}^{3}\right)$ but extremely low mtDNA content $(26 \%)$ and a long history of type 2 diabetes mellitus, hypertension, and coronary artery disease-features that typically reflect oxidative stress and mitochondrial dysfunction. Patient HE19 harboured nine more somatic mtDNA mutations in addition to an np433-438 C7 to C6 change. This patient had a small tumour $\left(2.6 \times 2 \times 2 \mathrm{~cm}^{3}\right)$ that contained slightly more mtDNA 


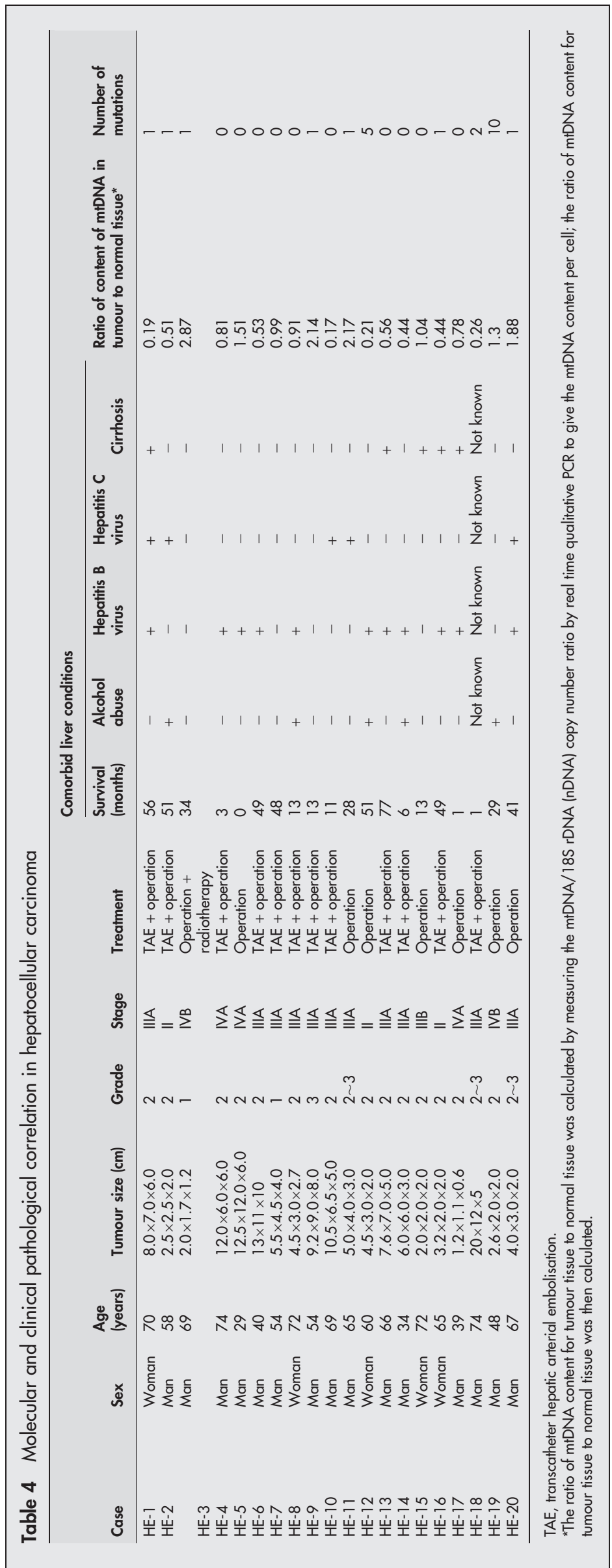


than the surrounding tissue (130\%). He was also relatively young: 48 years compared with 69 years for participant HE3 and 74 years for participant HE18. The effect of alterations at multiple nucleotide positions conceivably could be synergistic, additive, or inhibitory with respect to each other. To discover whether or not the poly $\mathrm{C}$ length at np433-438 or other mutations in the Dloop region, or both, affect mtDNA replication, transcription, or overall mitochondrial function will need more extensive studies.

In this study, we identified many germline variations. Although the biochemical consequence of homoplasmic polymorphisms is considered too subtle to cause any detectable effect on oxidative phosphorylation, long term accumulation of the subtle difference in oxidative phosphorylation activity may eventually result in oxidative stress. In the late onset of a disease such as cancer, for example, mtDNA polymorphisms potentially can play a role in modifying the risk of developing cancer. The missense variations $\mathrm{E} 32 \mathrm{~A}$ in $\mathrm{ND3}, \mathrm{S} 86 \mathrm{~A}$ in ND4, and A193T in cytochrome $\mathrm{b}$ could be modifiers of cancer risk. In the presence of alcohol abuse, subtle differences in respiratory efficiency may be augmented. Alcohol has been known to cause oxidative DNA damage. Our finding of significantly increased numbers of somatic mtDNA mutations in liver cancers in patients with history of alcohol abuse may support this notion.

\section{Conclusion}

We applied comprehensive mutation analysis to study somatic mtDNA mutations in patients with hepatocellular carcinomas and found that $50 \%$ of tumours harboured homoplasmic mutations or heteroplasmic mutations, or both. We identified mutations in the Dloop region that may affect mtDNA replication or transcription. Quantitative studies of mtDNA content showed that tumours with mtDNA mutations contained larger or smaller amounts of mtDNA than the surrounding tissues. The presence of hepatitis B infection, liver cirrhosis, or alcohol abuse, or their combinations, might result in qualitative or quantitative alterations in the amounts of mtDNA in tumours. These findings have important implications in the pathological role of mitochondria in human hepatocellular carcinoma in the presence or absence of associated liver disease.

\section{Authors' affiliations}

L-J C Wong, R-K Bai, Department of Oncology, Georgetown University Medical Center, Washington, DC, USA

K-T Yeh, J Chang, Department of Pathology, Changhua Christian Hospital, ChangHua, Taiwan

D-J Tan, Institute of Geriatric Cardiology, PLA General Hospital, Beijing, China 100853

Conflicts of interest: none declared.

Correspondence to: Dr Wong, Institute for Molecular and Human Genetics, Georgetown University Medical Center, M4000, 3800 Reservoir Rd, NW, Washington, DC 20007; wongli@georgetown.edu

Revised version received 18 August 2003

Accepted for publication 19 September 2003

\section{REFERENCES}

1 Wallace DC. Mitochondrial disease in man and mouse. Science 1999;283:1482-8.
2 Smeitink J, van den Heuvel L, DiMauro S. The genetics and pathology of oxidative phosphorylation. Nat Rev Genet 2001;2:342-52.

3 Tamura G, Nishizuka S, Maesawa C, Suzuki Y, Iwaya T, Sakata K, Endoh Y, Motoyama T. Mutations in mitochondrial control region DNA in gastric tumours of Japanese patients. Eur J Cancer 1999:35:316-9.

4 Tan D-J, Bai R, Wong L-JC. Comprehensive scanning of somatic mitochondrial DNA mutations in breast cancer. Cancer Res 2002;62:972-6.

5 Yeh JJ, Lunetta LK, van Orsouw NJ, Moore FDJ, Mutter GL, Vijg J, Dahia PLM, Eng C. Somatic mitochondrial DNA (mtDNA) mutations in papillary thyroid carcinomas and differential mtDNA sequence variants in cases with thyroid tumours. Oncogene 2000;19:2060-6.

6 Penta JS, Johnson FM, Wachsman T, Copeland WC. Mitochondrial DNA in human malignancy. Mutat Res 2001;488:119-33.

7 Polyak K, Li Y, Zhu H, Lengaver C, Willson JK, Markowitz SD, Trush MA, Kinzler KW, Vogelstein B. Somatic mutations of the mitochondrial genome in human colorectal tumours. Nature Genet 1998;20:291-3.

8 Liu VWS, Shi HH, Cheung ANY, Chiu PM, Leung TW, Nagley P, Wong LC, Ngan HYS. High incidence of somatic mitochondrial DNA mutations in human ovarian carcinomas. Cancer Res 2001;61:5998-6001.

9 Kirches E, Krause G, Warich-Kirches M, Weis S, Schneider T, Meyer-Puttlitz B, Mawrin C, Dietzmann K. High frequency of mitochondrial DNA mutations in glioblastoma multiforme identified by direct sequence comparison to blood samples. Int J Cancer 2001;93:534-8.

10 Hibi K, Nakayama H, Yamazaki T, Takase T, Taguchi M, Kasai Y, Ito K, Akiyama S, Nakao A. Mitochondrial DNA alteration in esophageal cancer. Int J Cancer 2001;92:319-21.

11 Fliss MS, Usadel H, Caballero OL, Wu L, Buta MR, Eleff SM, Jen J, Sidransky D. Facile detection of mitochondrial DNA mutations in tumors and bodily fluids. Science 2000;287:2017-9.

12 Habano W, Sugai T, Yoshida T, Nakamura S. Mitochondrial gene mutation, but not large-scale deletion, is a feature of colorectal carcinomas with mitochondrial microsatellite instability. Int J Cancer 1999;83:625-9.

13 Parrella $P$, Xiao Y, Fliss MS, Sanchez-Cespedes M, Mazzarelli P, Rinaldi M, Nicol T, Gabrielson E, Cuomo C, Cohen D, Pandit S, Spencer M, Rabitti C, Fazio VM, Sidransky D. Detection of mitochondrial DNA mutations in primary breast cancer and fine-needle aspirates. Cancer Res 2001;61:7623-6.

14 Richard SM, Bailliet G, Paez GL, Bianchi MS, Peltomaki P, Bianchi NO. Nuclear and mitochondrial genome instability in human breast cancer. Cancer Res 2000;60:4231-7.

15 Wong L-JC, Liang M-H, Kwon H, Park J, Bai R, Tan D. Comprehensive scanning of the whole mitochondrial genome for mutations. Clin Chem 2002;48:1901-12.

16 Wong L-JC, Lueth M, Li X-N, Lau CC, Vogel H. Detection of mitochondrial DNA mutations in the tumor and CSF of medulloblastoma patients. Cancer Res 2003;63:3866-71

17 Chen TJ, Boles R, Wong L-JC. Detection of mitochondrial DNA mutations by temporal temperature gradient gel electrophoresis. Clin Chem 1999;45:1162-7

18 Tan DJ, Chang J, Chen W-L, Agress L, Yeh K-T, Wang BT, Wong L-JC. Novel heteroplasmic frameshift and missense somatic mitochondrial DNA mutations in oral cancer of betel quid chewers. Gene, Chromosomes Cancer 2003;37:186-94.

19 Lueth M, Foster R, Kurtz A, Wong L-JC. Somatic mitochondrial DNA mutations are found in neurofibromatosis type 1. AACR Proceedings 2002;43:299

20 Nomoto S, Yamashita K, Koshikawa K, Nakao A, Sidransky D. Mitochondrial D-loop mutations as clonal markers in multicentric hepatocellular carcinoma and plasma. Clin Cancer Res 2002;8:481-7.

21 Okochi O, Hibi K, Uemura T, Inove S, Takeda S, Kaneko T, Nakao A Detection of mitochondrial DNA alterations in the serum of hepatocellular carcinoma patients. Clin Cancer Res 2002;8:2875-8.

22 Anderson S, Bankier AT, Barrell BG, deBruiin MHL, Coulson AR, Drouin J Eperon IC, Nierlich DP, Rose BA, Sanger F, Schreier PH, Smith AJH, Staden R, Young IG. Sequence and organization of the human mitochondrial genome. Nature $1981 ; 290: 457-65$.

23 Wong L-JC, Bai R. Real time quantitative PCR analysis of mitochondrial DNA in patients with mitochondrial disease. Am J Hum Genet 2002;71(suppl):501

24 Tan DJ, Agress L, Liu LL, Bai RK, Chang J, Wong L-JC. Somatic alterations of the mitochondrial genome in human hepatocellular carcinomas. Am J Hum Genet 2002;71(suppl):251.

25 Nishikawa M, Nishiguchi S, Shiomi S, Tamori A, Koh N, Takeda T, Kubo S Hirohashi K, Kinoshita H, Sato E, Inove M. Somatic mutation of mitochondrial DNA in cancerous and noncancerous liver tissue in individuals with hepatocellular carcinoma. Cancer Res 2001;61:1843-5.

26 Lee DY, Clayton DA. Initiation of mitchondrial DNA replication by transcription and R-loop processing. J Biol Chem 1998;273:30614-21.

27 Sanchez-Cespedes M, Parrella P, Nomoto S, Cohen D, Xiao Y, Esteller M, Jeronimo C, Jordan RC, Nicol T, Koch WM, Schoenberg M, Mazzarelli P, Fazio VM, Sidransky D. Identification of a mononucleotide repeat as a major target for mitochondrial DNA alterations in human tumors. Cancer Res 2001;61:7015-9. 